\title{
Metagenomic approach in study and treatment of various skin diseases: a brief review
}

\author{
Pragya Nagar and Yasha Hasija*
}

\begin{abstract}
Background: Skin is a complex ecosystem hosting a diverse microbial population as well as distinct environmental niches leading to hundreds of skin conditions that affect humans. There is an evident shift towards the metagenomic analysis from less efficient and strenuous culture-based techniques in biomedical research, thus creating a new dimension for dermatological study. A systematic and comprehensive study of skin microbiome appraises the dynamics between species, their interaction with the immune system, and composition in diseases.

Research: Metagenomics include research techniques like next-generation sequencing, sequencing of ampliconbased assays, shotgun metagenomics, gene prediction, metatranscriptomics, and statistical and comparative studies allowing us to access the functional and metabolic diversity of the skin microbiome and their role in host health. In disorders like acne, dandruff, seborrheic dermatitis, and bovine digital dermatitis, metagenomics provides information about the organisms present conferring the condition, inter-microbial interactions, and expression profiles of communities.

Conclusion: We have enriched our understanding of the uncultured world resulting in a better understanding of microbe interaction with each other and their host. Metagenomic analysis provides glimpses into topographical and interpersonal complexity that defines the skin microbiome. It has led to an advanced study of dermatological disorders like acne, dandruff, seborrheic dermatitis, atopic dermatitis, bovine digital dermatitis, and psoriasis, and this knowledge is a breakthrough in dermatology research for creating better therapeutic solutions and personalized treatments.
\end{abstract}

Keywords: Skin, Metagenomics, Microbiome, Dermatological disorders

\section{Background}

Skin is the first outermost layering representing a physical barrier to infections and potential assault by foreign organisms or toxic substances. This complex ecosystem is broadly composed of sebaceous areas (including the face and back); moist areas (including the toe/finger web space and arm pit); dry areas (including the forearm and buttock); sites containing varied densities of hair follicles, skin folds, and skin thicknesses; and characteristic host genetics (Wilantho et al. 2017). This confers to a suitable environment for harboring rich and diverse physiological populations of microorganisms. The

\footnotetext{
* Correspondence: yashahasija06@gmail.com

Department of Biotechnology, Delhi Technological University, Shahbad Daulatpur, Main Bawana Road, Delhi 110042, India
}

microbiome includes bacteria, fungi, viruses, parasites, and microeukaryotes which play significant role in dermatological disorders (Mathieu et al. 2013).

Previously, studies were done using culture-cultivated methods but have proved to be less efficient as less than $1 \%$ of bacterial species can be cultivated with standard lab conditions leading to a vast majority of microorganisms gone unnoticed (Chen and Tsao 2013). Hence, for an unbiased identifying and characterizing of skin microbiota and their genetic content, metagenomics and next-generation sequencing techniques are used (Mende et al. 2012). The term metagenome allows for the contribution of all the genes and genetic elements of the microorganisms in and on the host. Metagenomics refers to the structural and functional study of complex microbial communities and their interaction with the host (Virgin and Todd 2011). The

(c) The Author(s). 2018 Open Access This article is distributed under the terms of the Creative Commons Attribution 4.0 International License (http://creativecommons.org/licenses/by/4.0/), which permits unrestricted use, distribution, and 
objective of this study in characterizing the skin microbiome is to define the microbial community and study their consequences for better understanding of the skin diseases. This approach includes amplification, sequencing, and analysis of the hypervariable region of the prokaryotic $16 \mathrm{~S}$ rRNA gene as a proxy of the full-length gene and other phylogenetic marker genes (Rasheed et al. 2013). Oligonucleotide usage patterns can be utilized for identification of differences across complex microbial communities (Wan et al. 2017).

Metagenomic study permits collection, curation, and extraction of useful information from enormous datasets which is a significant computational challenge. Metagenomics include genomic DNA extraction, library construction, shotgun sequencing, taxonomic composition analysis, statistical analysis, etc (Fig. 1). This development has reframed our knowledge about the skin microbiome and its interactions with the host epithelial and immune system in various dermatological disorders (Kergourlay et al. 2015; Bzhalava et al. 2014; Martín et al. 2014), hence making way for the prevention and treatment of these diseases through diagnostic, prognostic, and therapeutic applications.

For instance, earlier it was believed that diseases like acne and dandruff were caused mainly due to the presence of Propionibacterium acnes and Malassezia fungi respectively. But several comprehensive metagenomic study findings have showed that the diseases are rather constituted by involvement of complex microbial communities and are detected by further taxonomic analysis (Barnard et al. 2016; Chng et al. 2016). Dermatological disorders which have been studied and analyzed through metagenomic approaches are acne vulgaris, dandruff, seborrheic dermatitis, atopic dermatitis, bovine digital dermatitis, psoriasis, vitiligo, melanoma, lupus erythematosus, basal cell carcinoma, erythema, and hidradenitis suppurativa (Table 1) (Actis \& Rosina 2013; Horton et al. 2015; Fyhrquist et al. 2016; Guet-Revillet et al. 2017; Kocarnik et al. 2015). This review covers our current knowledge on some of these dermatological disorders and potential aspect of metagenomics in dermatological research.

\section{Skin microbiome}

Skin represents a physical barrier to infection as a result of epidermis cohesion, protecting our bodies from potential assault by foreign organisms or toxic substances. There is a delicate balance between host and the skin microbiota including symbiotic bacteria, fungi, parasites, and viruses (Mathieu et al. 2013). Disruptions in the balance on either side can result in skin disorders. These diseases can be studied by characterizing the skin microbiota and analyzing how it interacts with the host (Hannigan and Grice 2013). The surface of the skin is cooler than the core body temperature and is slightly acidic, and squames are continuously shed from the skin surface as a result of terminal differentiation (Fuchs and Raghavan 2002). It mainly consists of sebaceous areas, moist areas, dry areas, and sites containing varied densities of hair follicles, skin folds, and skin thicknesses. Sebaceous glands being relatively anoxic support the growth of facultative anaerobes such as acne causing Propionibacterium acnes, which contain lipase-encoding genes that degrade skin lipids of sebum as revealed by full genome sequencing (Liu et al. 2015). Other dominant bacterial genera present in the skin are Staphylococcus and Corynebacterium. The major fungus found on the surface is the Malassezia (formerly known as Pityrosporum) genus which plays role in causing the common skin disease, dandruff, studied and confirmed by $18 \mathrm{~S}$

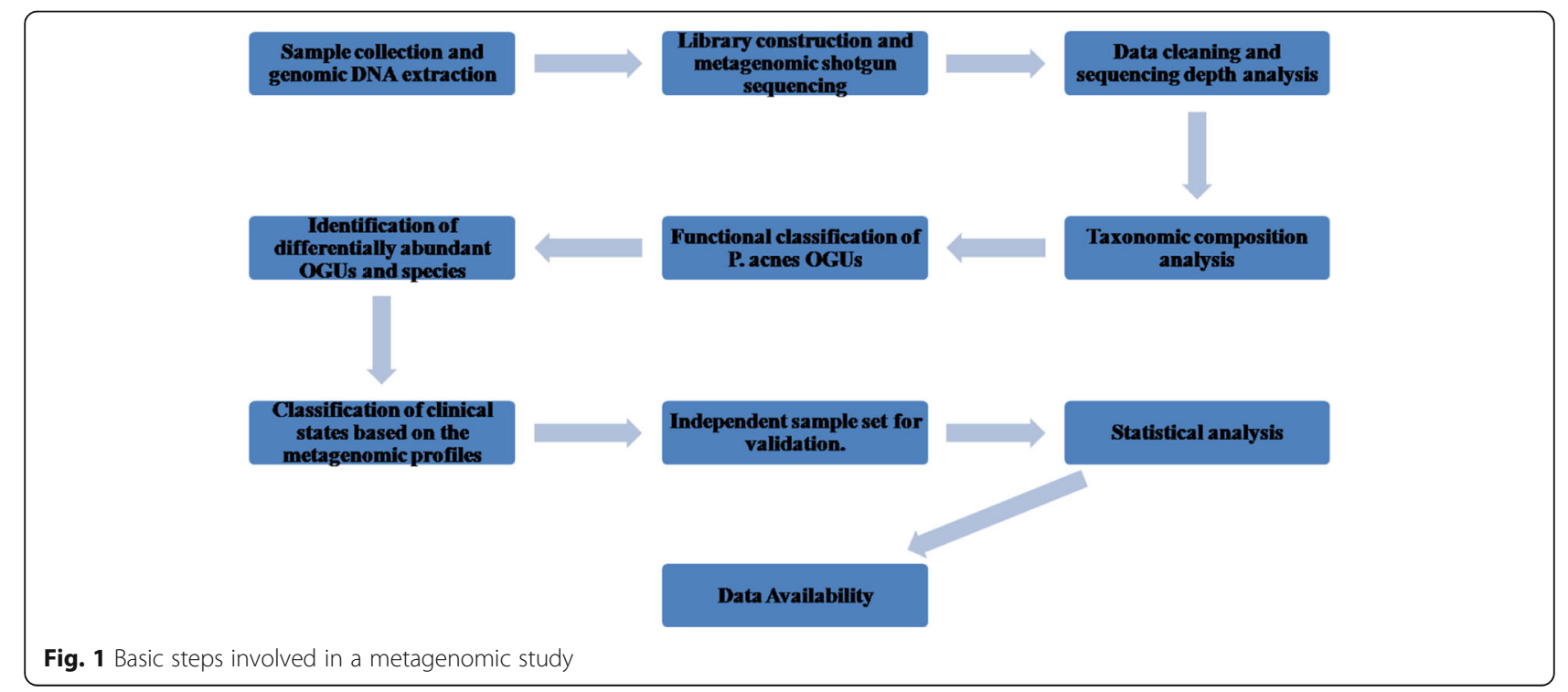


Table 1 List of diseases which have been studied using metagenomics

\begin{tabular}{ll}
\hline $\begin{array}{l}\text { Dermatological diseases in which metagenomic studies have } \\
\text { been done successfully }\end{array}$ & $\begin{array}{l}\text { Some common dermatological diseases with potential } \\
\text { metagenomic studies }\end{array}$ \\
\hline Acne vulgaris & Contact dermatitis \\
Seborrheic dermatitis & Skin rash \\
Atopic dermatitis & Wart \\
Bovine digital dermatitis & Keratosis \\
Psoriasis & Lichen planus \\
Vitiligo & Rosacea \\
Melanoma & Bullous pemphigoid \\
Lupus erythematosus & Melanocytic nevus \\
Basal cell carcinoma & Pemphigus \\
Erythema & Hyperpigmentation \\
Hidradenitis suppurativa & Ichthyosis \\
\hline
\end{tabular}

rRNA gene and ITS region sequencing (Tanaka et al. 2016). Whole-genome shotgun metagenomics has made it possible to study the skin viruses, most common being the human papillomavirus (HPV), human polyomaviruses (HPyVs), and circoviruses (Arroyo Mühr et al. 2015; Ma et al. 2014; Tse et al. 2012).

\section{Culture-independent techniques and personalized treatment approaches}

Earlier, the information and knowledge regarding the skin-associated microbes were primarily derived by culturing the microorganism and defining its phylogeny and taxonomy through phenotypic, microscopic, and biochemical relationships. But majority of microorganisms are retractile to cultivation or are unable to grow under the specified conditions, and thus, this approach significantly underestimates the complexity of the sample (Hugenholz et al. 1998). Hence, access to metagenomics has extensively fueled the growing segment of research in study and treatment of various dermatological disorders. Metagenomic analysis involves isolating DNA from an environmental sample or component under study, cloning the DNA into a suitable vector, transforming the clones into a host bacterium, and screening the resulting transformants for phylogenetic markers or "anchors," such as 16S rRNA and recA, for expression of certain traits like enzyme activity or antibiotic production, or for finding other conserved genes (Ferretti et al. 2017; Lau et al. 2017; Hannigan et al. 2015; Lane et al. 1985).

Metagenomic study generally includes preparation and sequencing of amplicon-based assays, shotgun metagenomics, primary computational analysis, and statistical and comparative studies (Kim et al. 2017). The shotgun metagenomic method comprises of collection and analysis of total DNA from the community without relying upon marker genes and sequencing directly
(Eisen, 2007). Another approach can be of consequent sequencing of amplified targeted microbial regions usually contained in the $16 \mathrm{~S}$ Rrna called ribosomal community profiling (Zinicola et al. 2015; Pace et al. 1985). Marker genes used in these techniques enclose both conserved regions, which allow for PCR primer binding and phylogenetic analysis, along with variable regions, whose sequences allow to be used for inferring the taxonomic composition of the community (Grice 2015).

Metatranscriptomics is a useful way to study species present in abundance as instead of DNA, RNA is obtained from a skin sample and then sequenced using next-generation sequencing (Baldrian et al. 2012; Poinar et al. 2006; Schuster, 2007). The transcriptome data provides this information better with the previously amplified RNA. Metatranscriptomic study detects majorly the live microorganisms due to unstable RNA sample as compared to DNA (Urich et al. 2008).

High-throughput sequencing technique does not require cloning of the DNA before sequencing, making the process less strenuous and time-consuming. Accuracy of assemblies obtained can be improved by correcting misassemblies using the paired-end tags by various assembly programs like Phrap assembler or velvet assembler (Chen and Pachter 2005). BLAST is used for rapid search of phylogenetic markers in existing databases used in MEGAN (Wooley et al. 2010). Sequences are binned, a process of association of a particular sequence with an organism, in order to perform comparative analysis of diversity using tools like PhymmBL, AMPHORA, and SLIMM which use individual reference genome to get reliable relative abundance by minimizing the false-positive hits (Kunin et al. 2008). There is an advent of faster and efficient tools like CLARK which can perform taxonomic annotation at extremely high speed than BLAST-based approaches like MG-RAST or MEGAN (Nicola et al. 2012). Comparison of obtained 
sequences against reference databases like KEGG can give functional comparisons between metagenomes (Mitra et al. 2011). Metagenomic study permits collection, curation, and extraction of useful information from enormous datasets which is a considerable computational challenge, hence leading to the analysis of functional potential of the skin microbiome, improvement of metabolic pathways, about genes encoding virulence and pathogenicity factors, and hence can be used for creating new therapeutic solutions to treat such diseases.

One major application of metagenomics in diseases are personalized medicine, defined as a medical procedure involving molecular profiling, medical imaging, and lifestyle data that separates patients into different groups-with medical decisions, practices, interventions and/or products being tailored to the individual patient based on their predicted response or risk of disease (Afshinnekoo et al. 2017). Thus, we have now the ability to affordably and rapidly generate large datasets which are used to interpret data obtained from microbial community via analytical tools and databases (Wylie et al. 2014). Such advanced study lead to the use of effective and safe probiotics (live microorganisms or their components that confer health benefits) for the use in skin diseases that may be influenced by the gut microbiota along with prebiotics consisting of substrates that promote the growth and/or metabolic activity of beneficial indigenous microbiota for treating skin diseases due to microbial cause (Grice 2015).

\section{Metagenomics in skin disorders}

\section{Acne}

Acne vulgaris (commonly called acne) is the most common skin disorder characterized by abnormalities of sebum production by the pilosebaceous unit (commonly known as the hair follicle), bacterial proliferation, and inflammation and affects $80-85 \%$ of the population (Barnard et al. 2016). This disease is most prevalent in adolescents (85\%) and rarely occurs in adults (11\%) (White 1998). Propionibacterium acnes is said to be an important pathogenic factor accounting for nearly $90 \%$ of the microbiota demonstrated by 16SrRNA metagenomic study along with other microbes Staphylococcus epidermidis, Propionibacterium humerusii, and Propionibacterium granulosum (Fitz-Gibbon et al. 2013).

After examining various healthy and acne patients, it was found that such human diseases are often caused by certain strains of a species, rather than the entire species being pathogenic. P. acnes contribute to skin health also by preventing the colonization of opportunistic pathogens as it maintains an acidic $\mathrm{pH}$ by converting sebum to free fatty acids (Liu et al. 2015). Thus, only some strains are related to acne and not all. The metagenomic approach in determining disease associations provides significant result as it is more commanding and less biased than traditional methods.

There was no statistically significant difference in the relative abundance of $P$. acnes found when comparison of acne patients and normal individuals was performed (Wilantho et al. 2017). The examination of differences at the strain level of $P$. acnes by defining each unique $16 \mathrm{~S}$ rDNA sequence as a $16 \mathrm{~S}$ rDNA allele type, called a ribotype (RT), was done and hence allowed us to compare the $P$. acnes strain populations in individuals (Barnard et al. 2016). The balance between acne and metagenomic elements determines the virulence and health properties of the skin microbiota in disease and health (Kwon and Suh 2016).

This study provides novel insights into the microbial environment and mechanism of acne pathogenesis and hence can lead to designing of probiotic and phage therapies as potential acne treatments for maintaining a healthy skin.

\section{Dandruff and seborrheic dermatitis (SD)}

Dandruff is a prevalent mild chronic inflammatory condition of the scalp characterized by itching and scaling of the skin on the scalp (Soares et al. 2016). Seborrheic dermatitis being considered the more severe form of dandruff affects areas other than the scalp with sebaceous glands like the face and chest. Generally, this includes events like dysbiosis and disruption of skin barrier and epidermal cellular proliferation and differentiation (Soares et al. 2016). This common disease affects approximately half the population of adults worldwide, mainly caused by the Malassezia fungi. But recent research has suggested that the microbial communities present are more complex (Byrd et al. 2017).

Several comprehensive analyses like next-generation sequencing (NGS), performed on healthy and dandruff-suffering scalps, have revealed that Propionibacterium, Staphylococcus, and Corynebacterium are the three most abundant genera in both healthy and dandruff subjects but with the Malassezia sp. being the vast majority of fungi. The most abundant, $M$. restricta along with $M$. globosa, $M$. sympodialis, $M$. dermatis, M. japonica, M. obtusa, M. pachydermatis, $M$. sloofiae, and M. furfur, were detected by further taxonomic analysis (Byrd et al. 2017). Metagenomic and molecular studies have shown that Propionibacterium acnes is found to be greater in healthy scalps while Staphylococcus epidermidis in dandruff scalp along with bacterial genera Pseudomonas, Leptotrichia, Micrococcus, Selenomonas, Erwinia, Enhydrobacter, and Bartonellaceae and fungal genera Candida, Aspergillus, and Filobasidium, and more Malassezia by $26 \mathrm{~S}$ r RNA molecular analysis (Wan et al. 2017) (Fig. 2). Further studies on scalp and forehead by high-throughput 16S rDNA and ITS1 sequencing, pyrosequencing, and 


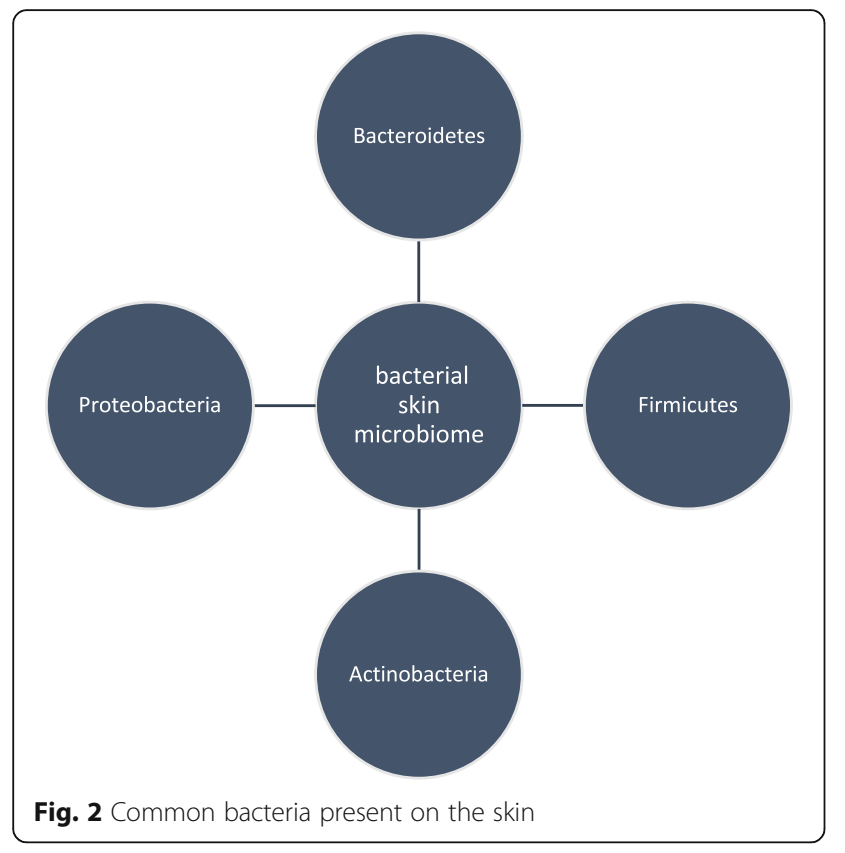

qPCR (Fig. 3) have shown that both lesional and non-lesional skin sites contain Acinetobacter, Corynebacterium, Staphylococcus, Streptococcus, and Propionibacterium with Propionibacterium being more abundant in non-lesional sites (Wan et al. 2017).

These technological advancements have increased our knowledge of the disease etiology and the role of the microbiome in the symptom development significantly in recent years which could be helpful for redefining the therapeutic approaches.

\section{Atopic dermatitis}

Atopic dermatitis (AD) is another frequently studied disease using metagenomics. AD is a chronic, noninfectious, recurring inflammatory disease characterized by itching and xerosis that affects majorly children (approximately 15\% children were affected in the USA). Effective treatments of this disease include antibiotics, corticosteroids, and dilute bleach baths (Huang et al. 2009). AD patients have an altered microbial community, and the pathogenesis is mainly associated with skin colonization by Staphylococcus aureus and immune hypersensitivity (Song et al. 2016; Weidinger et al. 2006). Filaggrin deficiency also plays role in $\mathrm{AD}$ as seen in mouse model with mutation in St14 that regulates filaggrin processing leading to increased Corynebacterium and Streptococcus and decreased Pseudomonas species (Scharschmidt et al. 2009). A 16S-rRNA-based metagenomic study of this disease has shown that both S. aureus and S. epidermidis increased in $\mathrm{AD}$ flares along with changes in abundance of some non-staphylococcal species leading to decreased bacterial diversity (Kong et al. 2012). There is domination of Staphylococcus, Pseudomonas, and Streptococcus in AD with Alcaligenaceae, Sediminibacterium, and Lactococcus being the characteristic of healthy skin, studied by high-throughput pyrosequencing on a Roche 454 GS-FLX

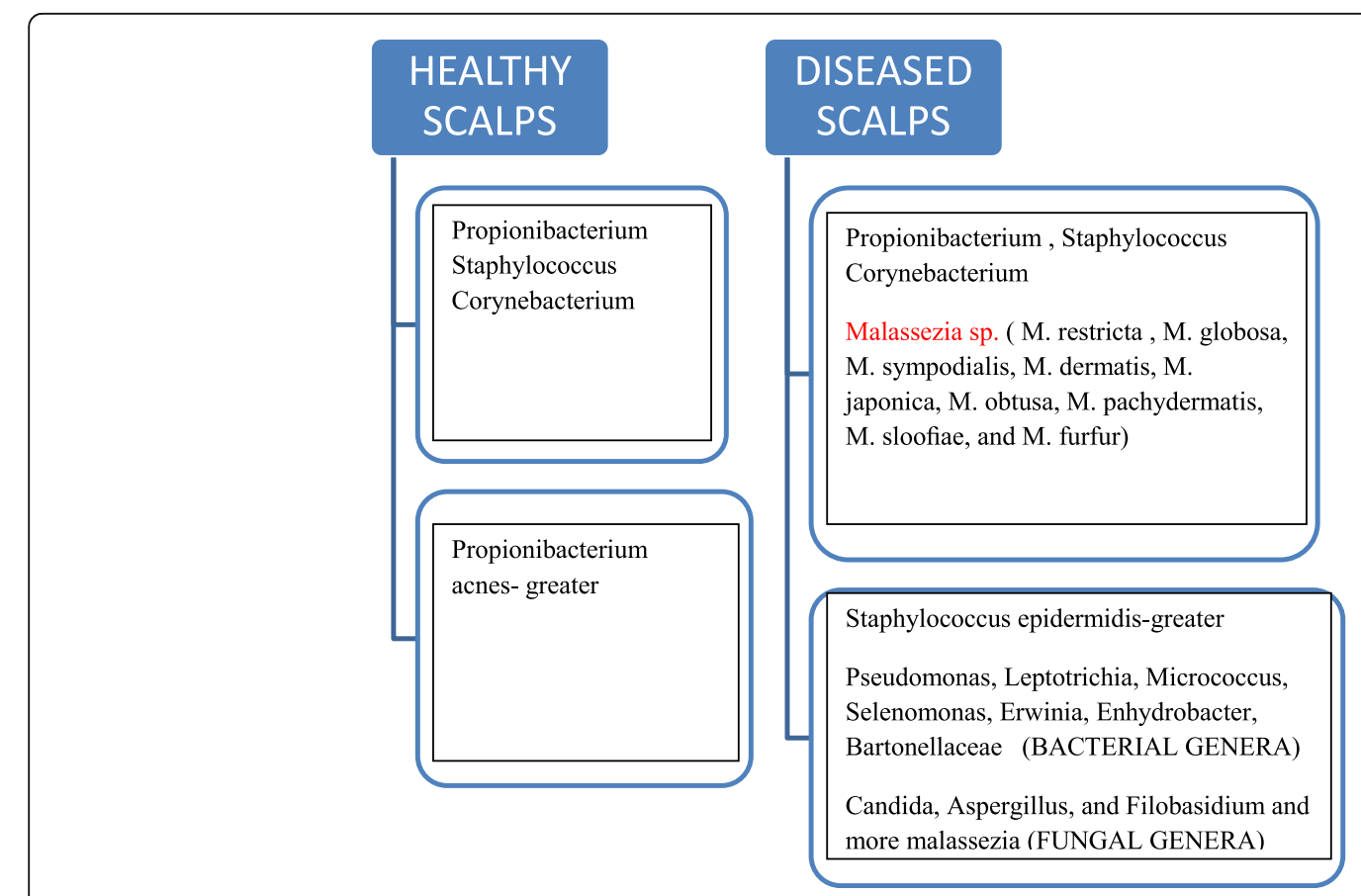

Fig. 3 Microbial genera present on healthy and dandruff subjects using next-generation sequencing (NGS), taxonomic analysis, high-throughput $16 \mathrm{~S}$ rDNA and ITS 1 sequencing, pyrosequencing, and $\mathrm{qPCR}$ 
platform (Kim et al. 2017). Hence, metagenomic analysis is important to study the action of these species and their association with the microbiome fluctuations and with one another. This will lead to designing of novel treatments like rebalancing of the skin microbiome.

\section{Psoriasis}

Psoriasis is a chronic inflammatory skin disease affecting about $2-3 \%$ of the world's population. Plaque psoriasis is the most common form of psoriasis affecting $85-90 \%$ of patients (Boehncke and Schon 2015). Although psoriasis is a skin disease, it can lead to development of psoriatic arthritis (PsA), metabolic syndromes, and cardiovascular diseases along with skin lesions (Grozdev et al. 2014). It has been known from the previously performed experiments that the immune system plays a key role in the disease pathogenesis. For PsA prevention in patients, the first step towards future development in therapeutics and early identification involves having the knowledge of the skin microbiome (Andersen et al. 2017; Castelino et al. 2014). Early culture-based studies identified Malassezia, group A and B beta-hemolytic streptococci, S. aureus, and Enterococcus faecalis being associated with the disease (Tett et al. 2017). 16S rRNA gene compositional analysis reveals that neonatal antibiotic treatment dysregulates skin microbiota and the imbalance is associated with development of experimental psoriasis. High-resolution shotgun metagenomics and finer strain-level analysis revealed decreased diversity and association of psoriasis with increase in Staphylococcus and its heterogeneity colonization and strain-level variability (Zanvit et al. 2015). Metagenomic study has been perceptive in understanding the taxonomic differences associated with psoriasis and hence offers the potential to overcome the limitations of culture-based studies.

\section{Bovine digital dermatitis}

It is a highly contagious infectious dermatitis with lesions near the interdigital spaces usually in cattle (Ganju et al. 2016). It causes discomfort and often severe lameness (LAMENESS, ANIMAL). Lesions can be either erosive or proliferative and wart-like with papillary growths and hypertrophied hairs. Dichelobacter nodosus and Treponema are the most commonly associated causative agents for this mixed bacterial infection disease (Drago et al. 2016; Krull et al. 2014) (year introduced, 2011).

\section{Conclusions}

Skin being the largest body organ leads to hundreds of skin conditions that have a significant impact on several aspects of human health and can lead to various skin disorders. It is vital to understand beneficial and harmful microorganisms and their mechanism. Advances in metagenomics and next-generation sequencing techniques have enhanced our ability to identify and characterize microbial communities colonizing the skin. It includes sensitive and rapid methods of sequencing to diagnose infection by comparing genetic material found in sample to a database of bacteria, viruses, and other pathogens. This field is promising in redefining therapeutic approaches for precision and personalized medicine and might transform management and treatment of dermatological disorders like acne vulgaris, seborrheic dermatitis, atopic dermatitis, psoriasis, and vitiligo by creating a broader view of disease etiology. However, for better diagnostic, prognostic, and therapeutic applications, further research is necessary to expand our understanding of healthy skin microbiota.

Funding

This work was supported by the Department of Biotechnology, Government of India [No. BT/PR5402/BID/7/508/2012]

\section{Authors' contributions}

$\mathrm{YH}$ conceived and designed the study. PN and $\mathrm{YH}$ wrote the manuscript. Both the authors approved the final manuscript.

Ethics approval and consent to participate

Not applicable.

\section{Competing interests}

The authors declare that they have no competing interests.

\section{Publisher's Note}

Springer Nature remains neutral with regard to jurisdictional claims in published maps and institutional affiliations.

Received: 14 January 2018 Accepted: 14 May 2018

Published online: 15 July 2018

References

Actis GC, Rosina F. Inflammatory bowel disease: an archetype disorder of outer environment sensor systems. World J Gastrointest Pharmacol Ther. 2013;4(3): 41-6. https://doi.org/10.4292/wjgpt.v4.i3.41. PMID: 23919214

Afshinnekoo E, Chou C, Alexander N, Ahsanuddin S, Schuetz AN, Mason CE. Precision metagenomics: rapid metagenomic analyses for infectious disease diagnostics and public health surveillance. J Biomol Tech. 2017;28(1):40-5. https://doi.org/10.7171/jbt.17-2801-007.

Andersen V, Holmskov U, Sørensen SB, et al. A proposal for a study on treatment selection and lifestyle recommendations in chronic inflammatory diseases: a Danish multidisciplinary collaboration on prognostic factors and personalised medicine. Nutrients. 2017;9(5):499. https://doi.org/10.3390/nu9050499.

Arroyo Mühr LS, Hultin E, Bzhalava D, Eklund C, Lagheden C, Ekström J, Johansson H, Forslund O, Dillner J. Human papillomavirus type 197 is commonly present in skin tumors. Int J Cancer. 2015;136(11):2546-55. https://doi.org/10.1002/ijc.29325. Epub 2014 Nov 25.PMID: 25388227

Baldrian P, Kolarik M, Stursova M, Kopecky J, Valaskova V, Vetrovsky T, et al. Active and total microbial communities in forest soil are largely different and highly stratified during decomposition. ISME J. 2012;6:248-58. [PubMed: 21776033]

Barnard E, Shi B, Kang D, Craft N, Li H. The balance of metagenomic elements shapes the skin microbiome in acne and health. Sci Rep. 2016;6:39491. https://doi.org/10.1038/srep39491. PMID: 28000755

Boehncke WH, Schon MP. Psoriasis. Lancet. 2015; https://doi.org/10.1016/S01406736(14) 61909-7.

Byrd AL, Deming C, Cassidy SKB, Harrison OJ, Ng WI, Conlan S, Comparative Sequencing Program NISC, Belkaid Y, Segre JA, Kong HH. Staphylococcus aureus and Staphylococcus epidermidis strain diversity underlying pediatric atopic dermatitis. Sci Transl Med. 2017;9(397) https://doi.org/10.1126/ scitransImed.aal4651. PMID: 28679656 
Bzhalava D, Mühr LS, Lagheden C, Ekström J, Forslund O, Dillner J, Hultin E. Deep sequencing extends the diversity of human papillomaviruses in human skin. Sci Rep. 2014;4:5807. https://doi.org/10.1038/srep05807.PMID: 25055967.

Castelino M, Eyre S, Upton M, Ho P, Barton A. The bacterial skin microbiome in psoriatic arthritis, an unexplored link in pathogenesis: challenges and opportunities offered by recent technological advances. Rheumatology (Oxford). 2014;53(5):777-84. https://doi.org/10.1093/rheumatology/ket319. Epub 2013 Sep 24. Review.PMID: 24067887

Chen K, Pachter L. Bioinformatics for whole-genome shotgun sequencing of microbial communities. PLoS Comput Biol. 2005;1(2):e24. https://doi.org/10 1371/journal.pcbi.0010024. PMC 1185649 Freely accessible. PMID 16110337

Chen $Y E$, Tsao $H$. The skin microbiome: current perspectives and future challenges. J Am Acad Dermatol. 2013;69(1):143-55. https://doi.org/10.1016/j. jaad.2013.01.016. Epub 2013 Mar 13. Review.PMID: 23489584

Chng KR, Tay AS, Li C, Ng AH, Wang J, Suri BK, Matta SA, McGovern N, Janela B, Wong XF, Sio YY, Au BV, Wilm A, De Sessions PF, Lim TC, Tang MB, Ginhoux F, Connolly JE, Lane EB, Chew FT, Common JE, Nagarajan N. Whole metagenome profiling reveals skin microbiome-dependent susceptibility to atopic dermatitis flare. Nat Microbiol. 2016;1(9):16106. https://doi.org/10.1038/ nmicrobiol.2016.106. PMID: 27562258

Drago L, De Grandi R, Altomare G, Pigatto P, Rossi O, Toscano M. Skin microbiota of first cousins affected by psoriasis and atopic dermatitis. Clin Mol Allergy. 2016;14:2. https://doi.org/10.1186/s12948-016-0038-z. eCollection 2016.PMID: 26811697

Eisen JA. Environmental shotgun sequencing: its potential and challenges for studying the hidden world of microbes. PLoS Biol. 2007;5(3):e82. https://doi.org/ 10.1371/journal.pbio.0050082. PMC 1821061 Freely accessible. PMID 17355177

Ferretti P, Farina S, Cristofolini M, Girolomoni G, Tett A, Segata N. Experimental metagenomics and ribosomal profiling of the human skin microbiome. Exp Dermatol. 2017;26(3):211-9. https://doi.org/10.1111/exd.13210. Epub 2017 Jan 20. Review.PMID: 27623553

Fitz-Gibbon S, Tomida S, Chiu BH, Nguyen L, Du C, Liu M, Elashoff D, Erfe MC, Loncaric A, Kim J, Modlin RL, Miller JF, Sodergren E, Craft N, Weinstock GM, Li $H$. Propionibacterium acnes strain populations in the human skin microbiome associated with acne. J Invest Dermatol. 2013;133(9):2152-60. https://doi.org/10.1038/jid.2013.21. Epub 2013 Jan 21.PMID: 23337890

Fuchs E, Raghavan S. Getting under the skin of epidermal morphogenesis. Nat Rev Genet. 2002;3:199-209. https://doi.org/10.1038/nrg758

Fyhrquist N, Salava A, Auvinen P, Lauerma A. Skin biomes. Curr Allergy Asthma Rep. 2016;16(5):40. https://doi.org/10.1007/s11882-016-0618-5. Review.PMID: 27056560

Ganju P, Nagpal S, Mohammed MH, Nishal Kumar P, Pandey R, Natarajan VT, Mande SS, Gokhale RS. Microbial community profiling shows dysbiosis in the lesional skin of vitiligo subjects. Sci Rep. 2016;6:18761. https://doi.org/10. 1038/srep18761. PMID: 26758568

Grice EA. The intersection of microbiome and host at the skin interface: genomic- and metagenomic-based insights. Genome Res. 2015;25(10):151420. https://doi.org/10.1101/gr.191320.115. PMID: 26430162

Grozdev I, Korman N, Tsankov N. Psoriasis as a systemic disease. Clin Dermatol. 2014;32:343-50

Guet-Revillet $H$, Jais JP, Ungeheuer MN, Coignard-Biehler H, Duchatelet S, Delage M, Lam T, Hovnanian A, Lortholary O, Nassif X, Nassif A, Join-Lambert O. The microbiological landscape of anaerobic infections in hidradenitis suppurativa: a prospective metagenomic study. Clin Infect Dis. 2017;65(2):282-91. https://doi.org/10.1093/cid/cix285. PMID: 28379372

Hannigan GD, Grice EA. Microbial ecology of the skin in the era of metagenomics and molecular microbiology. Cold Spring Harb Perspect Med. 2013;3(12):a015362. https://doi.org/10.1101/cshperspect.a015362. Review. PMID: 24296350

Hannigan GD, Meisel JS, Tyldsley AS, Zheng Q, Hodkinson BP, SanMiguel AJ, Minot S, Bushman FD, Grice EA. The human skin double-stranded DNA virome: topographical and temporal diversity, genetic enrichment, and dynamic associations with the host microbiome. MBio. 2015;6(5):e01578-15. https://doi.org/10.1128/mBio.01578-15. PMID: 26489866

Horton JM, Gao Z, Sullivan DM, Shopsin B, Perez-Perez GI, Blaser MJ. The cutaneous microbiome in outpatients presenting with acute skin abscesses. Horton J Infect Dis. 2015;211(12):1895-904. https://doi.org/10.1093/infdis/ jiv003. Epub 2015 Jan 12.PMID: 25583170

Huang JT, Abrams M, Tlougan B, Rademaker A, Paller AS. Treatment of Staphylococcus aureus colonization in atopic dermatitis decreases disease severity. Pediatrics. 2009;123:e808-14. [PubMed: 19403473]
Hugenholz P, Goebel BM, Pace NR. Impact of culture-independent studies on the emerging phylogenetic view of bacterial diversity. J Bacteriol. 1998;180(18): 4765-74. PMC 107498 Freely accessible. PMID 9733676

Kergourlay G, Taminiau B, Daube G, Champomier Vergès MC. Metagenomic insights into the dynamics of microbial communities in food. Int J Food Microbiol. 2015;213:31-9. https://doi.org/10.1016/j.jifoodmicro.2015.09.010. Epub 2015 Sep 16. Review.PMID: 26414193

Kim MH, Rho M, Choi JP, Choi HI, Park HK, Song WJ, Min TK, Cho SH, Cho YJ, Kim YK, Yang S, Pyun BY. A metagenomic analysis provides a culture-independent pathogen detection for atopic dermatitis. Allergy Asthma Immunol Res. 2017; 9(5):453-61. https://doi.org/10.4168/aair.2017.9.5.453. PMID: 28677360

Kocarnik JM, Park SL, Han J, Dumitrescu L, Cheng I, Wilkens LR, Schumacher FR, Kolonel L, Carlson CS, Crawford DC, Goodloe RJ, Dilks HH, Baker P, Richardson D, Matise TC, Ambite JL, Song F, Qureshi AA, Zhang M, Duggan D, Hutter C, Hindorff L, Bush WS, Kooperberg C, Le Marchand L, Peters U. Pleiotropic and sex-specific effects of cancer GWAS SNPs on melanoma risk in the population architecture using genomics and epidemiology (PAGE) study. PLoS One. 2015;10(3):e0120491. https://doi.org/10.1371/journal.pone. 0120491. eCollection 2015.PMID: 25789475

Kong HH, Oh J, Deming C, Conlan S, Grice EA, Beatson MA, et al. Temporal shifts in the skin microbiome associated with disease flares and treatment in children with atopic dermatitis. Genome Res. 2012;22:850-9. [PubMed: 22310478]

Krull AC, Shearer JK, Gorden PJ, Cooper VL, Phillips GJ, Plummer PJ. Deep sequencing analysis reveals temporal microbiota changes associated with development of bovine digital dermatitis. Infect Immun. 2014;82(8):3359-73. https://doi.org/10.1128/IAl.02077-14. Epub 2014 May 27.PMID: 24866801

Kunin V, Copeland A, Lapidus A, Mavromatis K, Hugenholtz P. A bioinformatician's guide to metagenomics. Microbiol Mol Biol Rev. 2008; 72(4):557-78. Table 578 Contents. doi:10.1128/MMBR.00009-08. PMC 2593568 Freely accessible. PMID 19052320

Kwon $\mathrm{HH}$, Suh DH. Recent progress in the research about Propionibacterium acnes strain diversity and acne: pathogen or bystander? Int J Dermatol. 2016; 55(11):1196-204. https://doi.org/10.1111/ijd.13282. Review.PMID: 27421121

Lane DJ, Pace B, Olsen GJ, Stahl DA, Sogin ML, Pace NR. Rapid determination of $16 \mathrm{~S}$ ribosomal RNA sequences for phylogenetic analyses. Proc Natl Acad Sci. 1985;82(20):6955-9. Bibcode:1985PNAS...82.6955L. doi:10.1073/pnas.82.20. 6955. PMC 391288 Freely accessible. PMID 2413450

Lau P, Cordey S, Brito F, Tirefort D, Petty TJ, Turin L, Guichebaron A, Docquier M, Zdobnov EM, Waldvogel-Abramowski S, Lecompte T, Kaiser L, PreynatSeauve O. Metagenomics analysis of red blood cell and fresh-frozen plasma units. Transfusion. 2017:57(7):1787-800. https://doi.org/10.1111/trf.14148. Epub 2017 May 11.PMID: 28497550

Liu J, Yan R, Zhong Q, Ngo S, Bangayan NJ, Nguyen L, Lui T, Liu M, Erfe MC, Craft $\mathrm{N}$, Tomida S, Li H. The diversity and host interactions of Propionibacterium acnes bacteriophages on human skin. ISME J. 2015;9(9):2078-93. https://doi. org/10.1038/ismej.2015.47. Epub 2015 Apr 7. Erratum in: ISME J. 2015 Sep; 9(9):2116.PMID: 25848871

Ma Y, Madupu R, Karaoz U, Nossa CW, Yang L, Yooseph S, Yachimski PS, Brodie EL, Nelson KE, Pei Z. Human papillomavirus community in healthy persons, defined by metagenomics analysis of human microbiome project shotgun sequencing data sets. J Virol. 2014;88(9):4786-97. https://doi.org/10.1128/JVI. 00093-14. Epub 2014 Feb 12.PMID: 24522917

Martín R, Miquel S, Langella P, Bermúdez-Humarán LG. The role of metagenomics in understanding the human microbiome in health and disease. Virulence. 2014;5(3):413-23. https://doi.org/10.4161/viru.27864. Epub 2014 Feb 11. Review.PMID: 24429972

Mathieu A, Delmont TO, Vogel TM, Robe P, Nalin R, Simonet P. Life on human surfaces: skin metagenomics. PLoS One. 2013;8(6):e65288. https://doi.org/10. 1371/journal.pone.0065288. Print 2013.PMID: 23776466

Mende DR, Waller AS, Sunagawa S, Järvelin Al, Chan MM, Arumugam M, Raes J, Bork P. Assessment of metagenomic assembly using simulated next generation sequencing data. PLoS One. 2012;7(2):e31386. Bibcode: 2012PLoSO...731386M. doi:10.1371/journal.pone.0031386. ISSN 1932-6203. PMC 3285633 Freely accessible. PMID 22384016

Mitra S, Rupek P, Richter DC, Urich T, Gilbert JA, Meyer F, Wilke A, Huson DH. Functional analysis of metagenomes and metatranscriptomes using SEED and KEGG. BMC Bioinformatics. 2011;12(Suppl 1):S21. https://doi.org/10.1186/ 1471-2105-12-S1-S21. ISSN 1471-2105. PMC 3044276 Freely accessible. PMID 21342551

Nicola S, Waldron L, Ballarini A, Narasimhan V, Jousson O, Huttenhower C. Metagenomic microbial community profiling using unique clade-specific 
marker genes. Nat Methods. 2012;9(8):811-4. https://doi.org/10.1038/nmeth 2066. PMC 3443552 Freely accessible. PMID 22688413

Pace NR, Stahl DA, Lane DJ, Olsen GJ. Analyzing natural microbial populations by rRNA sequences. ASM News. 1985;51:4-12. Archived from the original on 4 April 2012

Poinar HN, Schwarz C, Qi J, Shapiro B, Macphee RD, Buigues B, Tikhonov A, Huson D, Tomsho LP, Auch A, Rampp M, Miller W, Schuster SC. Metagenomics to paleogenomics: large-scale sequencing of mammoth DNA. Science. 2006;311(5759):392-4. https://doi.org/10.1126/science.1123360. Bibcode:2006Sci...311..392P

Rasheed Z, Rangwala H, Barbará D. 165 rRNA metagenome clustering and diversity estimation using locality sensitive hashing. BMC Syst Biol. 2013; 7(Suppl 4):S11. https://doi.org/10.1186/1752-0509-7-S4-S11. Epub 2013 Oct 23.PMID: 24565031

Tiffany C. Scharschmidt, Karin List, Elizabeth A. Grice, Roman Szabo, NISC Comparative Sequencing Program, Gabriel Renaud, Chyi-Chia R. Lee, Tyra G. Wolfsberg, Thomas H. Bugge, Julia A. Segre. Author manuscript; available in PMC 2010 Oct 1. J Invest Dermatol. 2009 129(10): 2435-2442. doi: https://doi. org/10.1038/jid.2009.104. PMCID: PMC2791707.

Schuster SC. Next-generation sequencing transforms today's biology. Nat Methods. 2007;5(1):16-8. https://doi.org/10.1038/nmeth1156.

Soares RC, Camargo-Penna PH, de Moraes VC, De Vecchi R, Clavaud C, Breton L, Braz AS, Paulino LC. Dysbiotic bacterial and fungal communities not restricted to clinically affected skin sites in dandruff. Front Cell Infect Microbiol. 2016;6:157. eCollection 2016.PMID: 27909689

Song H, Yoo Y, Hwang J, Na YC, Kim HS. Faecalibacterium prausnitzii subspecieslevel dysbiosis in the human gut microbiome underlying atopic dermatitis. J Allergy Clin Immunol. 2016;137(3):852-60. https://doi.org/10.1016/j.jaci.2015. 08.021. Epub 2015 Oct 1.PMID: 26431583

Tanaka A, Cho O, Saito C, Saito M, Tsuboi R, Sugita T. Comprehensive pyrosequencing analysis of the bacterial microbiota of the skin of patients with seborrheic dermatitis. Microbiol Immunol. 2016;60(8):521-6. https://doi. org/10.1111/1348-0421.12398.

Tett A, Pasolli E, Farina S, et al. Unexplored diversity and strain-level structure of the skin microbiome associated with psoriasis. NPJ Biofilms and Microbiomes. 2017:3:14. https://doi.org/10.1038/s41522-017-0022-5.

Tse H, Tsang AK, Tsoi HW, Leung AS, Ho CC, Lau SK, Woo PC, Yuen KY. Identification of a novel bat papillomavirus by metagenomics. PLoS One. 2012;7(8):e43986. https://doi.org/10.1371/journal.pone.0043986. Epub 2012 Aug 24.PMID: 22937142

Urich T, Lanzen A, Qi J, Huson DH, Schleper C, Schuster SC. Simultaneous assessment of soil microbial community structure and function through analysis of the meta-transcriptome. PLoS One. 2008;3:e2527. [PubMed: 18575584]

Virgin HW, Todd JA. Metagenomics and personalized medicine. Cell. 2011;147:44.

Wan TW, Higuchi W, Khokhlova OE, Hung WC, Iwao Y, Wakayama M, Inomata N, Takano T, Lin YT, Peryanova OV, Kojima KK, Salmina AB, Teng L, Yamamoto T. Genomic comparison between Staphylococcus aureus GN strains clinically isolated from a familial infection case: IS1272 transposition through a novel inverted repeat-replacing mechanism. PLoS One. 2017;12(11):e0187288. https://doi.org/10.1371/journal.pone.0187288. eCollection 2017.PMID: 29117225

Weidinger S, Illig T, Baurecht H, Irvine AD, Rodriguez E, Diaz-Lacava A, et al. Lossof-function variations within the filaggrin gene predispose for atopic dermatitis with allergic sensitizations. J Allergy Clin Immunol. 2006;118:214-9. [PubMed: 16815158]

White GM. Recent findings in the epidemiologic evidence, classification, and subtypes of acne vulgaris. J Am Acad Dermatol. 1998;39(2 Pt 3):S34-S37

Wilantho A, Deekaew P, Srisuttiyakorn C, Tongsima S, Somboonna N. Diversity of bacterial communities on the facial skin of different age-group Thai males. Peer J. 2017;5:e4084. https://doi.org/10.7717/peerj.4084. eCollection 2017. PMID: 29177119

Wooley JC, Godzik A, Friedberg I. A primer on metagenomics. PLoS Comput Biol. 2010;6(2):e1000667. https://doi.org/10.1371/journal.pcbi.1000667. PMC 2829047 Freely accessible. PMID 20195499. Bourne, Philip E., ed

Wylie KM, Mihindukulasuriya KA, Zhou Y, Sodergren E, Storch GA, Weinstock GM. Metagenomic analysis of double-stranded DNA viruses in healthy adults. BMC Biol. 2014;12:71. https://doi.org/10.1186/s12915-014-0071-7. PMID: 25212266

Zanvit P, Konkel JE, Jiao X, Kasagi S, Zhang D, Wu R, Chia C, Ajami NJ, Smith DP, Petrosino JF, Abbatiello B, Nakatsukasa H, Chen Q, Belkaid Y, Chen ZJ, Chen
W. Antibiotics in neonatal life increase murine susceptibility to experimental psoriasis. Nat Commun. 2015;6:8424. https://doi.org/10.1038/ncomms9424. PMID: 26416167

Zinicola M, Higgins H, Lima S, Machado V, Guard C, Bicalho R. Shotgun metagenomic sequencing reveals functional genes and microbiome associated with bovine digital dermatitis. PLoS One. 2015;10(7):e0133674. https://doi.org/10.1371/journal.pone.0133674. eCollection 2015.PMID: 26193110

\section{Ready to submit your research? Choose BMC and benefit from:}

- fast, convenient online submission

- thorough peer review by experienced researchers in your field

- rapid publication on acceptance

- support for research data, including large and complex data types

- gold Open Access which fosters wider collaboration and increased citations

- maximum visibility for your research: over $100 \mathrm{M}$ website views per year

At BMC, research is always in progress.

Learn more biomedcentral.com/submissions 